\title{
Design of Unified Power Quality Conditioner (UPQC) for Power Quality Improvement in Distribution System
}

\author{
K.Sandhya ${ }^{1}$, Dr.A.Jayalaxmi ${ }^{2}$, Dr.M.P.Soni ${ }^{3}$ \\ ${ }^{1}$ Research Scholar, Department of Electrical and Electronics Engineering, JNTU college of Engineering, \\ Hyderabad, AP, INDIA, \\ ${ }^{2}$ Associate professor, Department of Electrical and Electronics Engineering, JNTU college of Engineering, \\ Hyderabad, AP, INDIA, \\ ${ }^{3}$ Professor and Head, Department of Electrical and Electronics Engineering, MJ college of Engineering and \\ Technology, Banjarahills, Hyderabad, AP, INDIA,
}

\begin{abstract}
Power Quality problems have received a great attention nowadays because of their bad economical impacts on both utilities and customers. This paper presents the influence of Unified Power Quality Conditioner $(U P Q C)$ on power quality issues. The UPQC is relatively a new number of the custom power device family. It is a custom power device with integrated shunt and series active filters. The UPQC makes use of two IGBT based voltage source bidirectional converters with a common dc bus. The performance of UPQC is examined by considering three phase unbalances in source as well as load current. The simulation results are investigated using MATLAB simulation.
\end{abstract}

Keywords: Custom Power Devices, IGBT, Power Quality, Voltage unbalances and UPQC.

\section{INTRODUCTION}

The quality power supply is essential for proper operation of industrial processes which contain critical and sensitive loads. The numbers of loads which are very sensitive to PQ problems have increased in the modern power system and at the same time the number of PQ polluting factors has also escalated. The increased penetration of distributed generation sources in to the power system has further contributed to existing PQ complexities. These distributed generation sites are often fuelled by renewable energy sources such as wind and solar. The random nature of these energy sources poses a reliability threat to the power system.

There are two approaches to the mitigation of power quality problems. The first approach is called load conditioning, which ensures that the equipment is made less sensitive to power disturbances, allowing the operation even under significant voltage distortion. The other solution is to install line-conditioning systems that suppress or counteract the power system disturbances. The simplest method of harmonic filtering is with passive filters. They use reactive storage components namely capacitors and inductors. Among the more commonly used passive filters are the shunt-tuned LC filters and the shunt low-pass LC filters. They have some advantages such as simplicity, reliability, efficiency and cost. However, their performance is limited to a few harmonics and they can introduce resonance in the power system. These drawbacks are overcome with the use of active power filters. A Unified Power Quality Conditioner (UPQC) is an integration of shunt active power filter and series active power filter. The cost of the device is higher than that of other custom power devices, because of twin converter structure and control complexity. Distribution Generation such as wind generation field is the place where UPQC can find its potential application.

\section{CUSTOM POWER TECHNOLOGY}

As the power quality problems are originated from utility and customer side, the solutions should come from both and are named as utility based solutions and customer based solutions respectively. The best examples for those two types of solutions are FACTS devices (Flexible AC Transmission Systems) and Custom power devices. FACTS devices are those controlled by the utility, whereas the Custom power devices are operated, maintained and controlled by the customer itself and installed at the customer premises. Both the FACTS devices and Custom power devices are based on solid state power electronic components. As the new technologies emerged, the manufacturing cost and the reliability of those solid state devices are improved; hence the protection devices which incorporate such solid state devices can be purchased at a reasonable price with better performance than the other electrical or pneumatic devices available in the market. Some of these Custom Power Devices are: Series-connected compensator like DVR (Dynamic Voltage Restorer), Shunt-connected compensator like DSTATCOM (Distribution STATic COMpensator), Series and shunt compensator like UPQC (Unified Power Quality Conditioner) and SSTS (Solid State Transfer Switch). Among these, the UPQC is an effective custom power solution which consists of two back to back connected IGBT based voltage sourced bidirectional converters with a common DC bus. 


\section{UNIFIED POWER QUALITY CONDITIONER}

Unified Power Quality Conditioner (UPQC) is an integration of shunt active power filter and series active power filter. The basic circuit of UPQC is shown in Fig.1. The series portion compensates for supply voltage harmonics and voltage unbalances, acts as a harmonic blocking filter and damps power system oscillations. The shunt portion compensates load current harmonics, reactive power and load current unbalances. In addition, it regulates the DC link capacitor voltage. The power supplied or absorbed by the shunt portion is the power required by the series compensator and the power required to cover losses. A Unified Power Quality Conditioner that operates in simultaneous voltage and current control modes. UPQC combines the operations of a Distribution Static Compensator (DSTATCOM) and Dynamic Voltage Restorer (DVR) together. In the voltage control mode it can make bus voltage at load terminal sinusoidal against any unbalance, harmonic or flicker in the source voltage or unbalance or harmonic in the load current. In the current control mode, it draws a balanced sinusoidal current from the utility bus irrespective of unbalance and harmonic in either source voltage or load current.

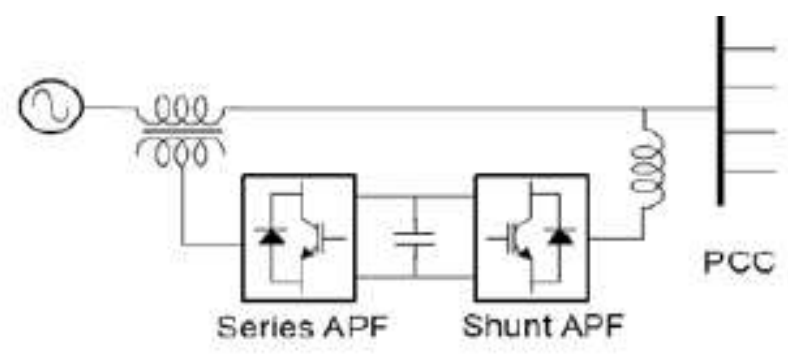

Fig.1 General configuration of UPQC

In present case UPQC with right shunt topology is considered. In right shunt topology, shunt active power filter will come right side of series active power filter that is near to load so that the currents flowing through the series transformers will be balanced sinusoidal. UPQC voltage references are calculated based on Fourier series, extraction of fundamental sequence components using half cycle running (moving) averaging, current references are calculated using the instantaneous symmetrical component theory. At the PCC of shunt active power filter, the voltage is load voltage which is balanced sinusoidal after compensating the source voltages by series active power filter. So we can use the instantaneous symmetrical component theory for calculating the source reference currents, which will be in phase with the load voltage, so that source will supply only average active power, remaining part of oscillating active power and total reactive power will be supplied by the UPQC. A mathematical model for UPQC with right shunt topology considering non-linearity in load is derived.

\section{UPQC IN POWER DISTRIBUTION SYSTEM}

A UPQC compensated distribution system is shown in Fig.2. It consists of load that is supplied by a source through a feeder. The load voltage is denoted by $v_{1}$ and the source voltage by $v_{\mathrm{s}}$, the resistance $R_{\mathrm{S}}$ and feeder impedance by $L_{\mathrm{s}}$. It is to be noted that this impedance can also be the Thevenin's impedance looking into the network from the Point of Common Coupling (PCC). In that event $v_{\mathrm{s}}$ would be the Thevenin's voltage.The voltage at the point of common coupling is denoted by the terminal voltage $v_{t}$. The idealized UPQC combines the current source $i_{f}$ and the voltage source $v_{d}$. The purpose of the series voltage source of the UPQC is to insert voltage $v_{d}$ such that the load voltage $v_{l}$ is a balanced sinusoid irrespective of unbalance or distortion in the terminal voltage $v_{t}$. On the other hand, the purpose of the shunt current source is to inject current $i_{f}$ such that the source current $i_{s}$ is balanced and distortion free irrespective of the shape of the load current $i_{l}$. The UPQC must therefore provide a steady voltage to the load terminal and at the same time draw pure sine wave current from the source irrespective of unbalance or distortion in the system quantities. Furthermore, we stipulate that the UPQC must be controlled using the local variables only, which in this case are the terminal voltage, load and source currents.

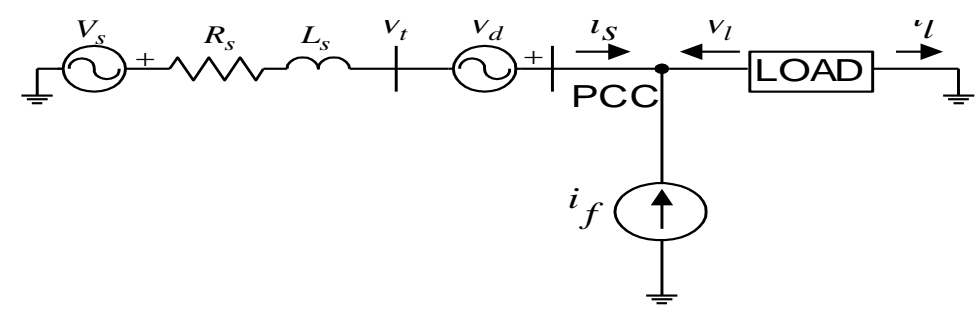

Fig.2 UPQC compensated distribution system 


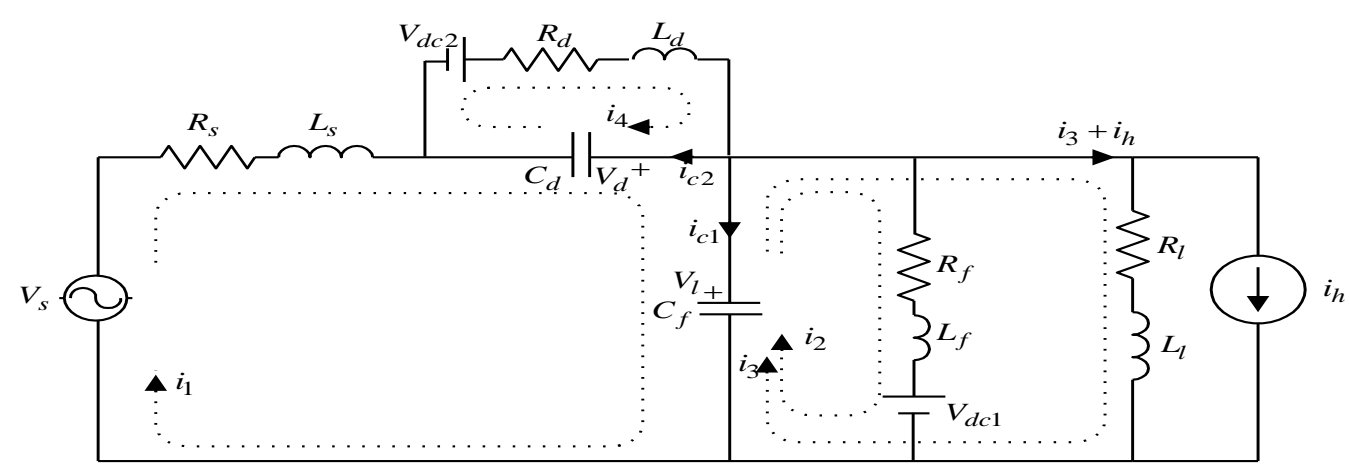

Fig.3 Equivalent circuit of UPQC compensated system

In this section the control design for the system is presented which is shown in Fig.3. The equivalent circuit of the compensated system is shown in Fig.4. Inductance $L_{\mathrm{f}}$ in this figure represents additional external inductance to get smooth filter current. The inductance $L_{\mathrm{d}}$ is the leakage inductance of the series transformer. The switching losses of an inverter and the copper loss of the connecting transformer are represented by a resistance $R_{\mathrm{f}}$ and $R_{\mathrm{d}}$. The iron losses of the transformer are neglected. The load is a combination of linear $R L$ load characterized by $R_{\mathrm{l}}$ and $L_{\mathrm{l}}$ and rectifier load represented by $i_{\mathrm{h}}$. The voltage sources $V_{\text {d.c. } 1}$ and $V_{\text {d.c. } 2}$ are the voltage $V_{\text {d.c. }}$ across the d.c. storage capacitor multiplied by the switch function of the shunt and series inverters respectively.

The state-space equation of the circuit then can be written as

$\dot{x}=A x+B_{1} v_{s}+B_{2} u+B_{3} i_{h}$

V. COMPENSATION STRATEGY

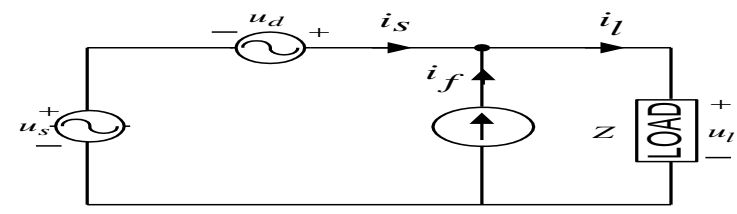

Fig.4 Equivalent circuit of UPQC

Fig. 4 shows an equivalent circuit for the industrial power system installing UPQC on the common bus, where $u_{s}$ is the power supply, $u_{d}$ is the series-APF compensating voltage and $u_{l}$ is the load voltage, $i_{f}$ is the shunt-APF compensating current and $\mathrm{Z}$ represents the non-linear load of the system. Distorted voltages in a 3-phase system may contain negative phase sequence and harmonic components. The voltage of phase "a" shown in Fig. 3.5 can be expressed as, in general:

$$
\begin{aligned}
u_{s a}(t)=u_{1 p a}(t)+u_{1 n a}(t)+\sum_{k=2}^{\infty} u_{k a}(t) \\
=U_{1 p} \sin \left(\omega t+\theta_{1 p}\right)+U_{1 n} \sin \left(\omega t+\theta_{1 n}\right)+\sum_{k=2}^{\infty} U_{k a} \sin \left(k \omega t+\theta_{k a}\right)
\end{aligned}
$$

where $u_{l p a}$ is the fundamental frequency positive sequence component while $u_{I n l}$ is the negative sequence component. $U_{l p}$ and $U_{l n}$ are the positive, negative sequence voltages amplitudes respectively. $\theta$ is the initial phase of voltage. The last term of the above equation represents the harmonics in the voltage. From Fig.4 , the source voltage can be expressed as:

$$
u_{s a}+u_{d a}=u_{l a}
$$

Since the load voltage is to be perfectly sinusoidal and balanced one with fixed amplitude $U$, the output voltages of the series-APF should be

$$
u_{d a}=\left(U-U_{1 p}\right) \sin \left(\omega t+\theta_{1 p}\right)-u_{1 n a}(t)-\sum_{k=2}^{\infty} u_{k a}(t)
$$

The series-APF can be designed to operate as a controlled voltage source whose output voltage would be automatically controlled according to the above equation. 
To provide load reactive power demand and compensation of the load harmonic and negative sequence currents, the shunt-APF acts as a controlled current source and its output components should include harmonic, reactive and negative-sequence components in order to compensate these quantities in the load current. In other words, if the load current of phase " $a$ " is expressed as

$$
\begin{aligned}
i_{a l} & =I_{1 p} \sin \left(\omega t+\psi_{1 p}\right)+i_{a 1 n}+\sum_{k=2}^{\infty} i_{a l k} \\
& =I_{1 p} \sin \left(\omega t+\theta_{1 p}\right) \cos \phi_{1 p}+i_{a 1 n l}+I_{1 p} \cos \left(\omega t+\theta_{1 p}\right) \sin \phi_{1 p}+\sum_{k=2}^{\infty} i_{a l k}
\end{aligned}
$$

Where $\phi_{1 p}$ is the initial phase of current and $\phi_{1 p}=\psi_{1 p}-\theta_{1 p}$

When the output current of shunt-APF $i_{f a}$ is made equal to the component of the load current which is given by the following equation:

$$
i_{f a}=I_{1 p} \cos \left(\omega t+\theta_{1 p}\right) \sin \phi_{1 p}+i_{a 1 n l}+\sum_{k=2}^{\infty} i_{a l k}
$$

The harmonic, reactive and negative-sequence current will not flow into power source. Hence, the current from the source terminal will be

$$
i_{s a}=i_{l a}-i_{f a}=I_{1 p} \sin \left(\omega t+\theta_{1 p}\right) \cos \phi_{1 p}
$$

This is a perfect, harmonic-free sinusoid and has the same phase angle as the phase "a" voltage at the load terminal. The UPQC configured taking right shunt topology into account. A state space model has been developed. A compensation strategy has been developed. Fourier series method for series reference filter voltages and instantaneous symmetrical component theory for shunt reference filter currents has been derived.

\section{RESULTS}

Simulation results are shown for unbalanced source and unbalanced load. From the waveforms shown in fig. 5 and fig.6, it is observed that source voltages and load currents are unbalanced. The terminal voltages are obtained after subtracting the voltage drop in the source impedance $Z_{\mathrm{s}}$ which are also unbalanced.

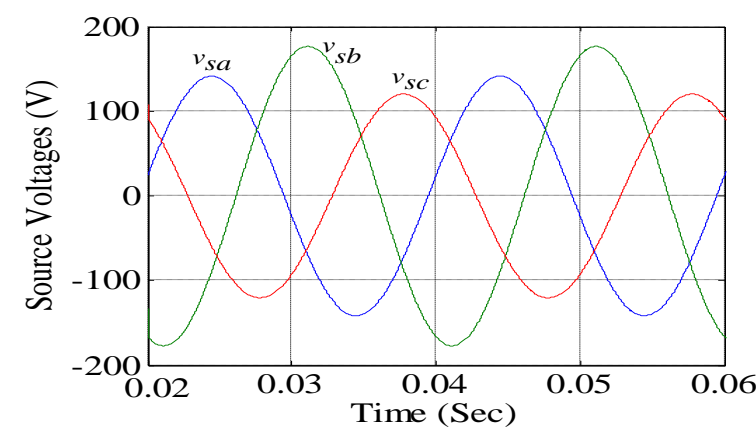

Fig.5 Unbalanced source voltages

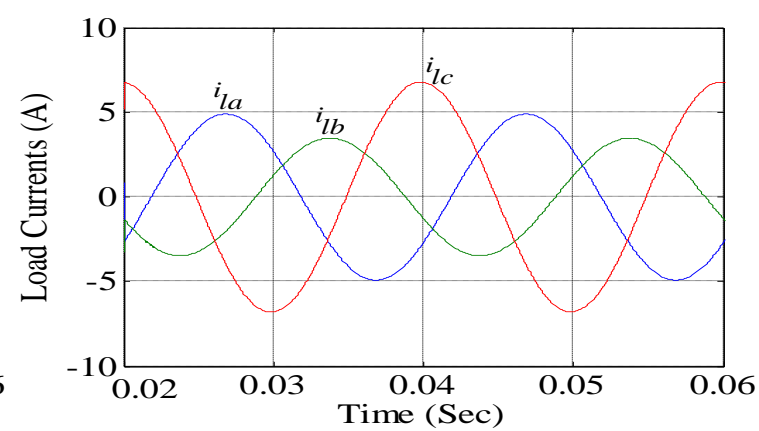

Fig.6 Unbalanced load currents

The series injected filter voltages which contain the voltage which is to be compensated and some ripple voltage which is due to the inverter switching operation is shown in below Fig. 7. The shunt injected filter currents are shown in Fig. 8.

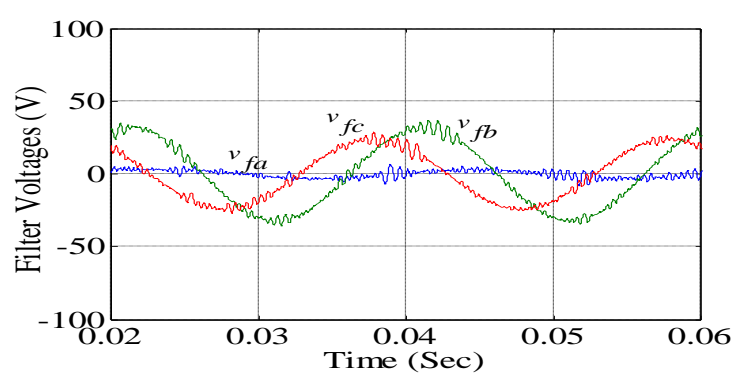

Fig.7 Series injected filter voltages

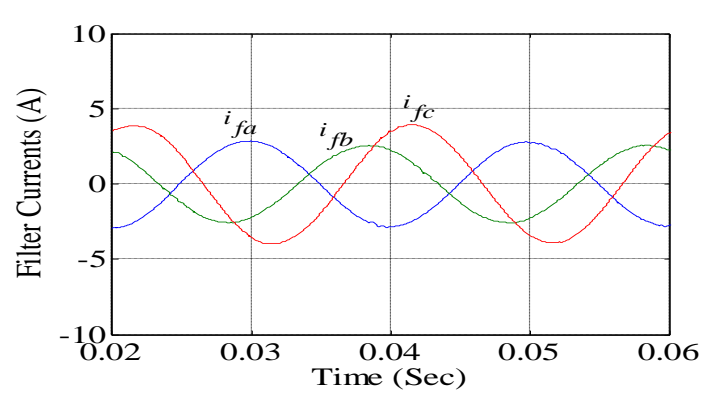

Fig.8 Shunt injected filter currents

The load voltages and source currents which are balanced and sinusoidal after compensation are shown in below Fig. 9 and Fig. 10. 


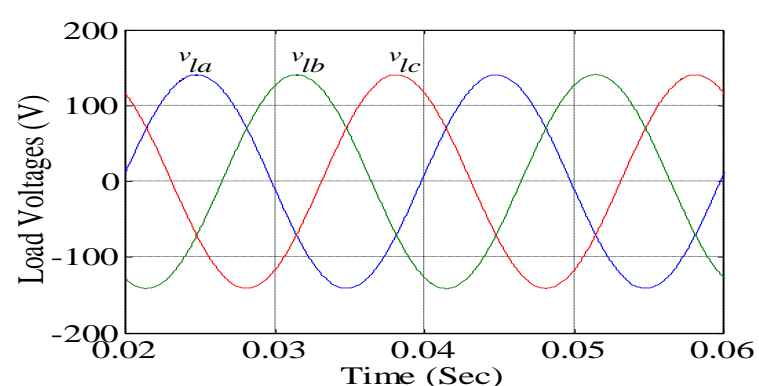

Fig.9 Load voltage

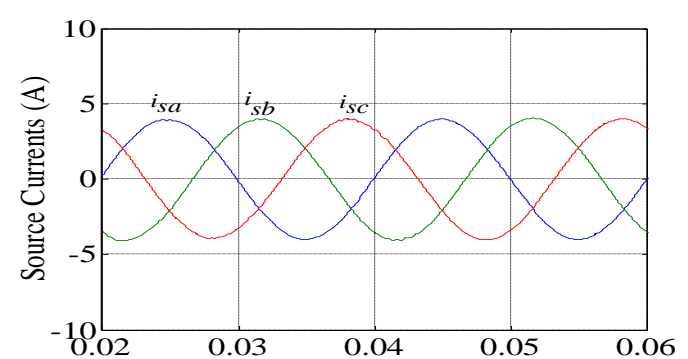

Fig.10 Source current

From the above wave forms it is observed that the load voltage and source currents are balanced, sinusoidal and in-phase. So the UPQC is able to compensate the unbalance in source voltage, load current and improves the power factor also. The \% THD content in the load voltage and source current after compensation are very less as is shown in Table 1.

\begin{tabular}{|c|c|c|c|}
\hline \% THD content in & Phase $-a$ & Phase $-b$ & Phase $-c$ \\
\hline Load voltages & 0.09 & 0.08 & 0.09 \\
\hline Source voltage & 0.00 & 0.00 & 0.00 \\
\hline Source currents & 0.84 & 0.48 & 0.85 \\
\hline
\end{tabular}

Table 1: \% THD content in load voltages and source currents after compensation

\section{CONCLUSION}

This paper presents the design of Unified Power Quality Conditioner. The UPQC is configured taking right shunt topology into account. A state space model has been developed. A compensation strategy has been developed. Fourier series method for series reference filter voltages and instantaneous symmetrical component theory for shunt reference filter currents has been derived. Simulation results are shown for unbalanced source and unbalanced load. The load voltages and source currents which are balanced and sinusoidal after compensation. So the UPQC is able to compensate the unbalance in source voltage, load current and improves the power factor also. The \%THD content in the load voltages and source currents after compensation are very less.

\section{REFERENCES}

[1] Hugh Rudnick, Juan Dixon and Luis Moran, "Delivering Clean and Pure Power," IEEE Power and Energy Magazine, Vol.1 Sep-Oct 2003, pp. 32-40.

[2] Arindam Ghosh, Gerard Ledwich, "A unified power quality conditioner (UPQC) for simultaneous voltage and current compensation," Electric Power Systems Research, Vol. 59, June 2001, pp. 55-63.

[3] Arindam Ghosh, Amit Kumar Jindal and Avinash Joshi, "A Unified Power Quality Conditioner for Voltage Regulation of Critical Load Bus," Power Engineering Society General Meeting, 2004, IEEE, Vol. 1, June 2004, pp. 471-476.

[4] Gu Jianjun, Xu Dianguo, Liu Hankui and Gong Maozhong, "Unified Power Quality Conditioner (UPQC): the principle, Control and Application," Power Conversion Conference, 2002. Vol.1, April 2002, pp.80-85.

[5] A. Elnady and M. M. A Salama, "New Functionalities of the Unified Power Quality Conditioner," Transmission and Distribution Conference and Exposition, 2001 IEEE/PES, Vol. 1, 28 Oct-2 Nov. 2001, pp. 415-420.

[6] Arindam Ghosh, Avinash Joshi, "The use of instantaneous symmetrical components for balancing a delta connected load and power factor correction," Electric Power Systems Research,Vol.54, Aug1999, pp67-74.

[7] Mahesh K., Mishra, A. Ghosh and A. Joshi, "Load compensation for system with non-stiff source using state feedback," Electric Power System Research, Vol. 67, Issue 1, Oct 2003, pp. 35-44.

[8] Mahesh K. Mishra, A. Ghosh A. Joshi and H. M. Suryawanshi, "A Novel Method of Load Compensation under Unbalanced and Distorted Voltages," Accepted for IEEE Trans. on Power Delivery.

[9] Nasiri A., Emadi A. "Different topologies for single phase unified power quality conditioners," Industry Applications Conference, 2003, Vol. 2, October 2003, pp. 976-981.

\section{BIOGRAPHIES}

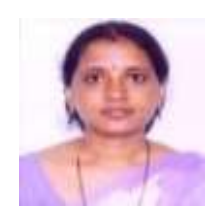

K.Sandhya, obtained B.Tech. in 2001 and M.Tech. in 2007 with specialization in Electrical Power Systems from Jawaharlal Nehru Technological University and pursuing Ph.D. (Power Quality) from Jawaharlal Nehru Technological University, Hyderabad, India. She has 10 years of teaching experience. Her research interests are Power Systems, Power Quality, FACTS and Custom Power Devices. She has 8 international and national conference papers to her credit. She is a Member of Indian Society of Technical Education (M.I.S.T.E). 


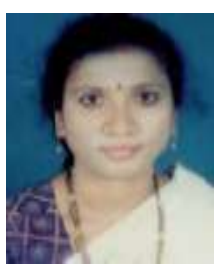

Dr. A. Jayalaxmi, completed her B.Tech (EEE) from Osmania University College of Engineering, Hyderabad in 1991, M.Tech.(Power Systems) from REC Warangal, Andhra Pradesh in 1996 and completed Ph.D. (Power Quality) from Jawaharlal Nehru Technological University College of Engineering, Hyderabad in 2007. She has five years of Industrial experience and 14 years of teaching experience. She has worked as Visiting Faculty at Osmania University College of Engineering, Hyderabad and is presently working as Associate Professor, Department of Electrical and Electronics Engineering, JNTU College of Engineering, Hyderabad. She has 60 International and 10 National papers published in various conferences held at India and also abroad. She has350 international journal papers and 5 national journals \& magazines to her credit. Her research interests are Neural Networks, Power Systems \& Power Quality. She was awarded "Best Technical Paper Award" for Electrical Engineering in Institution of Electrical Engineers in the year 2006. Dr. A. Jaya laxmi is a Fellow of Institution of Electrical Engineers Calcutta (F.I.E), Member of Indian Society of Technical Education (M.I.S.T.E), Member of System Society of India (M.S.S.I), Member IEEE, Member International Accredition Organization (IAO), Member of Institution of Electronics and Telecommunication Engineers (MIETE) and also Member of Indian Science Congress.

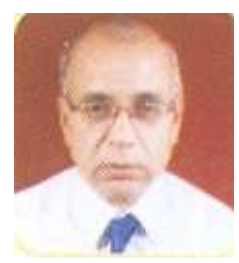

Dr. M. P. Soni Worked as Addl. General Manager in BHEL (R \& D) in Transmission and power System Protection. Worked as Senior Research Fellow at I.I.T. Bombay for BARC Sponsored Project titled, 'Nuclear Power Plant Control' during the year 1974 - 1977. Presently Working as Professor and Head, Department of Electrical and Electronics Engineering, M.J. College of Engineering and Technology, Banjarahills, Hyderabad. India. He has undertaken the following projects like "Dynamic Simulation Studies on Power System and Power Plant Equipments", "Initiated developments in the area of Numerical Relays for Substation Protection", "Developed Microprocessor based Filter bank protection for National HVDC Project and commissioned at $220 \mathrm{kV}$ Substation s ,MPEB Barsoor and APTRANSCO Lower Sileru, Terminal Stations of the HVDC Project. "Commissioned Numerical Relays and Low cost SCADA System at 132kV, GPX Main Distribution Substation, BHEL Bhopal". He has 20 international and national conference papers to his credit. His research interests include power System protection and advanced control systems. 